P0100

\title{
COMPACT REFERENCE UV-LEDS SOURCES WITH CONICAL DIFFUSE REFLECTOR
}

\author{
Siarhey Nikanenka et al. \\ DOI 10.25039/x46.2019.PO100 \\ from \\ CIE x046:2019 \\ Proceedings \\ of the \\ 29th CIE SESSION \\ Washington D.C., USA, June 14 - 22, 2019 \\ (DOI 10.25039/x46.2019)
}

The paper has been presented at the 29th CIE Session, Washington D.C., USA, June 14-22, 2019. It has not been peer-reviewed by CIE.

(c) CIE 2019

All rights reserved. Unless otherwise specified, no part of this publication may be reproduced or utilized in any form or by any means, electronic or mechanical, including photocopying and microfilm, without permission in writing from CIE Central Bureau at the address below. Any mention of organizations or products does not imply endorsement by the CIE.

This paper is made available open access for individual use. However, in all other cases all rights are reserved unless explicit permission is sought from and given by the $\mathrm{CIE}$.

CIE Central Bureau

Babenbergerstrasse 9

A-1010 Vienna

Austria

Tel.: +43 17143187

e-mail: ciecb@cie.co.at

www.cie.co.at 


\title{
COMPACT REFERENCE UV-LEDS SOURCES WITH CONICAL DIFFUSE REFLECTOR
}

\author{
Nikanenka, S.V., Danilchyk, A.V.,Lutsenko, E.V. \\ B.I. Stepanov Institute of Physics National Academy of Sciences of Belarus, Minsk, BELARUS \\ s.nikonenko@dragon.bas-net.by
}

DOI 10.25039/x46.2019.PO100

\begin{abstract}
At present time, radiation measurements in UV range are non-uniform and the measurement uncertainties are high. One of the promising ways to improve the accuracy of measurements in the UV range is the use of reference radiation sources created on the basis of LEDs, due to their stability and long lifetime. In this work the compact UV-LED sources with conical type of diffuse reflectors for UV-A, UV-B and UV-C ranges, which is created by B.I. Stepanov Institute of Physics National Academy of Sciences of Belarus we describe. The optical characteristics of the compact reference UV-LED sources were considered.
\end{abstract}

Keywords: ultraviolet, UV-LED, reference source

\section{Introduction}

Ultraviolet (UV) sources are nowadays widely used in a numerous applications: chemical identification, polygraphy and photopolymerization, medicine and defectoscopy, etc. The efficiency, quality and safety of work performed using UV radiation, is largely determined by the quality of the preliminary metrological support of these works. There are a number of problems in metrological support in the UV region. First of all, it is a significant reduction in the accuracy of the transfer of measured units size from national standards of the corresponding optical quantities to working measurement tools in the UV-A radiation range (from 400 to $315 \mathrm{~nm}$ ) and $B$ (from 315 to $280 \mathrm{~nm}$ ) and C (from 280 to $200 \mathrm{~nm}$ ). Second, when measuring in the UV-A, UV-B and UV-C ranges, it is necessary to use a power meter with constant spectral sensitivity inside these ranges and zero outside it, which is very problematic due to the lack of high-quality UV filters. Third, the accuracy of the results of measuring optical characteristics of UV radiation is reduced significantly due to the difference in spectral distributions of the radiation intensity of the test and reference radiation sources (CIE 2015). It can be predicted that in the next 5 years, traditional sources of UV radiation will be replaced by UV-LEDs in many applications. However, the previously developed methods of measuring the characteristics and parameters of optical radiation are not fully applicable to the LEDs emission.

One of the promising ways to improve the accuracy of optical measurements in the UV spectral region is the use of reference radiation sources created on the basis of UV-LEDs, due to their stability and long lifetime.

\section{Design of reference UV-LED sources}

Earlier, we developed of reference UV-A LED source with hemispherical diffuser (Nikanenka, 2017). These hemispherical sources allow you to create a uniform illumination, but require for their work significant considerable optical power from UV-LEDs. Currently, efficient UV-LEDs $(365 \mathrm{~nm})$ can reach a power of more than $5 \mathrm{~W}$ (NICHIA), which is enough to create reference hemispheric sources.

If recently for UV-B and UV-C ranges UV-LEDs, the power was about $0.1 \mathrm{~mW}$, the quantum efficiency was about $1 \%$ and the lifetime was 100 hours. Now their radiation power has increased to several tens of $\mathrm{mW}$, quantum efficiency up to $10 \%$, and lifetime (L70) up to 10,000 hours. Thus, on base of the modern LEDs of the UV-B and UV-C ranges currently can be to make reference sources for these spectral ranges. However, since there are rather large 
losses in the hemispherical source due to light scattering and the LEDs have small radiation powers. Therefore the designs of reference sources that provide direct illumination of measurement plane by with LEDs was created.

These are compact reference UV-LED sources with cylindrical and conical diffusers (RUS 2011, RUS 2012). Figure 1 shows the design of such reference sources. It should be noted that these sources can be used with or without a holographic filter installed on the output aperture.

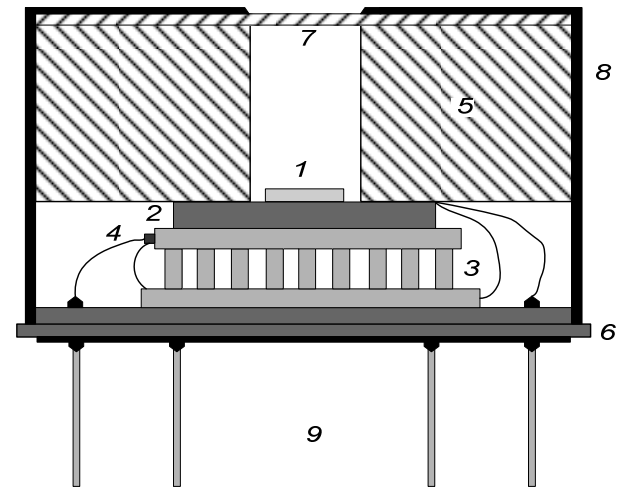

a

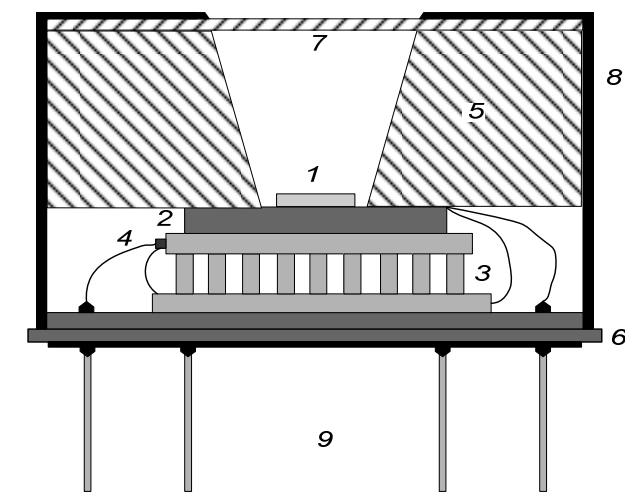

b

Figure 1 - Design of compact reference cylindrical a) and conical b) UV reference LED source

Compact reference UV reference LED sources contains: 1 - LED chip mounted on a heat sink housing 2 with a flat back side; 3 - Peltier element; 4 - thermistor; 5 - diffusor; 6 - housing base; 7 - holographic filter (may not be included); 8 - cover; 9 - contact pads of LED power, Peltier element and a thermistor.

The created sources of reference radiation used UV LEDs VPC131 and VPS1A1, emitting at 265 and $300 \mathrm{~nm}$, respectively, with a maximum optical radiation power of about $12 \mathrm{~mW}(\lambda=$ $265 \mathrm{~nm})$ and $25 \mathrm{~mW}(\lambda=300 \mathrm{~nm})$ at a injection current of $500 \mathrm{~mA}$. The LED NC4U133A-E $(365 \mathrm{~nm})$, ther is maximum optical power being $\sim 2000 \mathrm{~mW}$ at a injection current of $700 \mathrm{~mA}$.

UV-LED with a thermistor, were mounted on a heat-dissipating base plate and fixed on a Peltier element. This provides the ability to control the temperature of the LED casing with an accuracy of $0.001{ }^{\circ} \mathrm{C}$ by using serially produced temperature controllers Arroyo TECsource 5305.

On the front side of the LED casing is a diffuse cylindrical or conical forms reflector, the inner surface which is highly reflective. The resulting structure is mounted on the housing base and is closed by a housing cover on which a holografic filter can be fixed to create an uniform radiance. Source includes one LED.

The reference UV- LED sources design allows to increase the stability of its optical characteristics and to increase lifetime, due to the thermal stabilization of LED, which also helps to minimize the measurement errors of optical characteristics. In this case, the combination of a diffuse reflector and a holographic filter ensures uniform distribution of LED radiation power within the standard angles of a photometric observer.

The picture of compact reference UV-LED sources is shown in figure 2. 


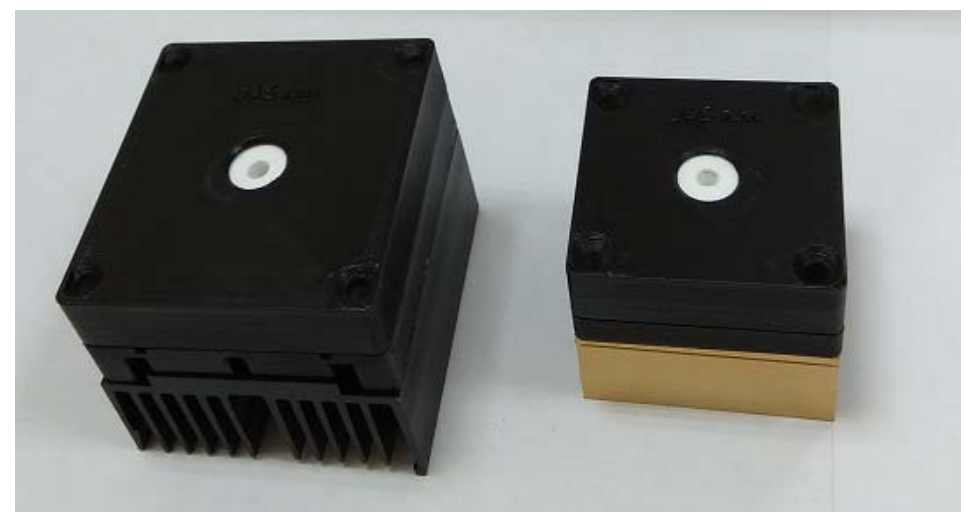

Figure 2 -Picture of compact reference UV-LED sources

\section{Measurement setup}

The measurement of optical characteristics of reference UV-LED sources was carried out using setup for the measurement of optical characteristics of UV-NIR SSL emission sources (Nikanenka, 2014). Setup was developed and built in the Institute of Physics. The main metrological characteristics of the measurement setup were established: the spectral range of the radiation power measurement is from $200 \mathrm{~nm}$ to $1100 \mathrm{~nm}$; the deviation angles in two perpendicular planes are $\pm 110^{\circ}$ and $360^{\circ}$; the relative expanded uncertainty of the rotation angle reproduction range of the rotation angle is $0.08 \%$; the measurement relative combined uncertainty of luminous intensity spatial distribution is $1.04 \%$; the relative combined uncertainty of LED spectral irradiance measurement in the spectral range from $250 \mathrm{~nm}$ to 900 $\mathrm{nm}$ is less than $2.8 \%$; the range of measurement of LED spectral irradiance is from 0.0001 to $10000 \mathrm{~mW} \cdot \mathrm{m}^{-2} \mathrm{~nm}^{-1}$; the relative combined uncertainty of LED spectral radiance measurement in spectral range from $250 \mathrm{~nm}$ to $500 \mathrm{~nm}$ is less than $3.5 \%$; the range of measurement of LED spectral radiance is from $10^{2}$ to $10^{12} \mathrm{~W} \cdot \mathrm{m}^{-3} \mathrm{sr}^{-1}$. All testings of the compact reference UVLED sources were performed at $25^{\circ} \mathrm{C}$.

Before measurements, all LEDs were aged during 50 hours. Spatial distribution of spectral irradiance of the reference LED source of $365 \mathrm{~nm}$ was measured at the distance $500 \mathrm{~mm}$ from the surface of holographic filter. Measurements were performed on the area of $3 \times 3 \mathrm{~cm}^{2}$, which is much larger than the characteristic photosensitive area of typical photodetectors used in precision optical radiometry, with $2 \mathrm{~mm}$ steps using photodiode head was limited by a $1 \mathrm{~mm}$ calibrated aperture. The standard deviation was about $0.4 \%$, and the standard error was about $0.2 \%$ within the measurement area.

\section{Optical characteristics of the reference UV-LED sources}

Results of the investigation of the optical characteristics of reference UV-LED sources performances are presented in figures $3-7$.

The spectrum of reference UV LED sources is shown in Figure 3. As can be seen from the figure, there is a slight overlap of the spectral distribution of radiation from different UV ranges. So $4.17 \%$ of the intensity of the reference source UV-C falls into the range of UV-B. And $2.17 \%$ and $0.4 \%$ of the intensity of the reference source UV-B fall within the ranges of UV-A and UV-C, respectively. Thus, the range overlap is negligible and the suggested sources may be suitable for precision UV metrology. 


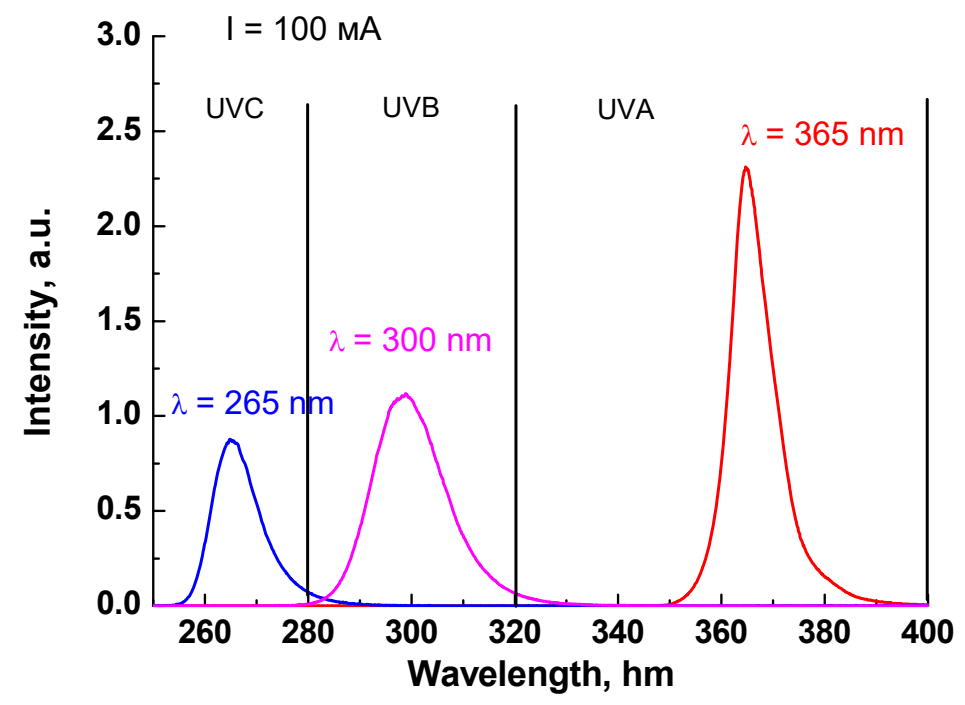

Figure 3 - Spectrum of reference UV LED source

As can be seen from the figure 4 - 6 the use of a conical diffuser leads to a significant increase in the radiation power density in comparison with cylindrical diffuser. For UV-C and UV-B UV-LED sources, this value is about $30 \%$, due to the ratio of the light channel to the thickness of the diffuser and, accordingly, a large number of reflections. The larger angle of spatial radiation of last mentioned source, compared to the sources at 265 and $300 \mathrm{~nm}$, is due to the large LED with 4 chips and thus it needs larger diameter of the reflector. 

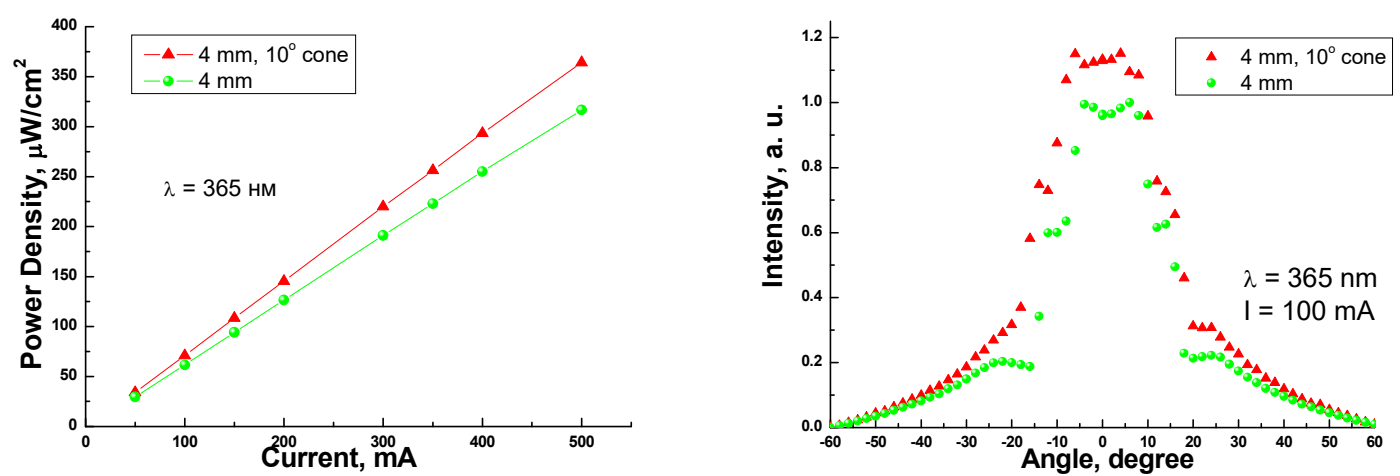

a)

b)

Figure 4 - Power density as a function of injection current a) and Intensity as a function of observation angle b) of reference UV-A LED source
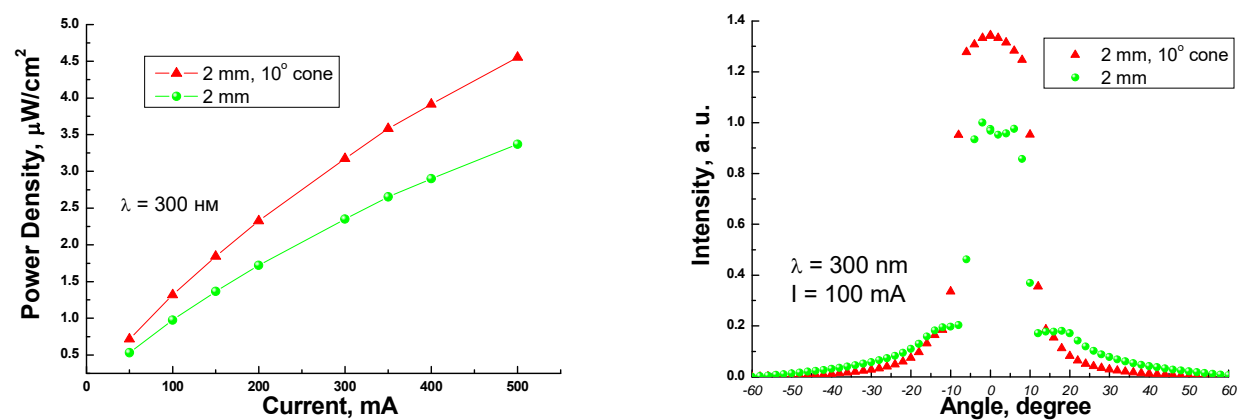

a)

b)

Figure 5 - Power density as a function of injection current a) and Intensity as a function of observation angle b) of reference UV-B LED source
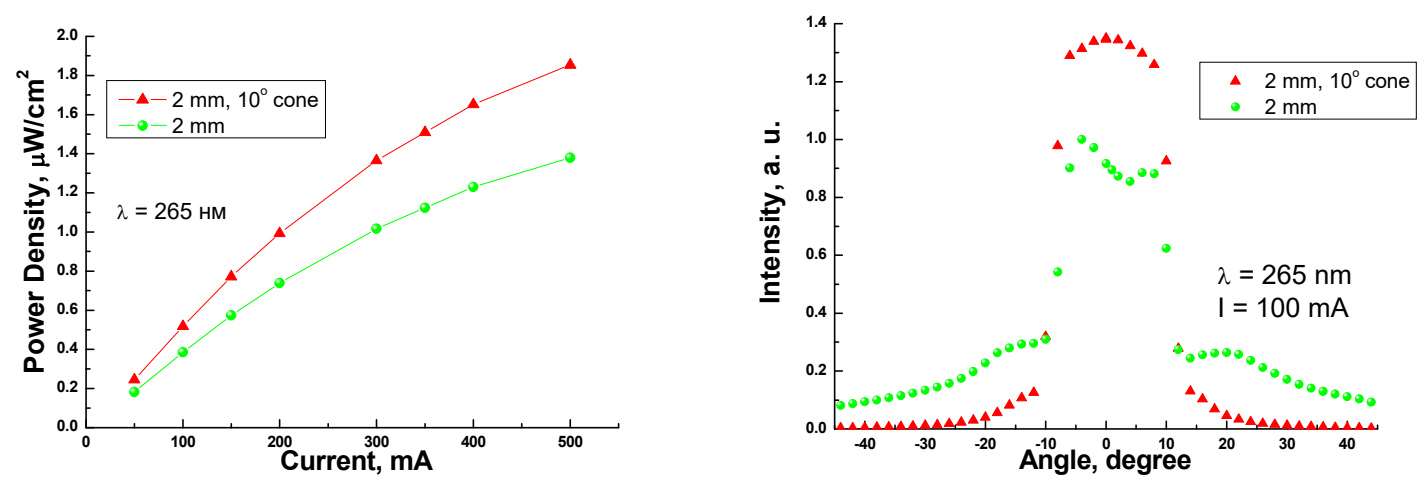

a)

b)

Figure 6 - Power density as a function of injection current a) and angular distribution of intensity b) of reference UV-C LED source

The intensity of the reference LEDs is within $\pm 10^{\circ}$ from the optical axis for 265 and $300 \mathrm{~nm}$, and about $\pm 15^{\circ}$ for $365 \mathrm{~nm}$. The values of the optical radiation density power at wavelengths of $265 \mathrm{~nm}, 300 \mathrm{~nm}$ and $365 \mathrm{~nm}$ with FWHM $10.5 \mathrm{~nm}, 16 \mathrm{~nm}$ and $9.5 \mathrm{~nm}$ were witch 1,17 $\mathrm{W} / \mathrm{m}^{2}, 2,86 \mathrm{~W} / \mathrm{m}^{2}$ and $229,03 \mathrm{~W} / \mathrm{m}^{2}$ respectively. 


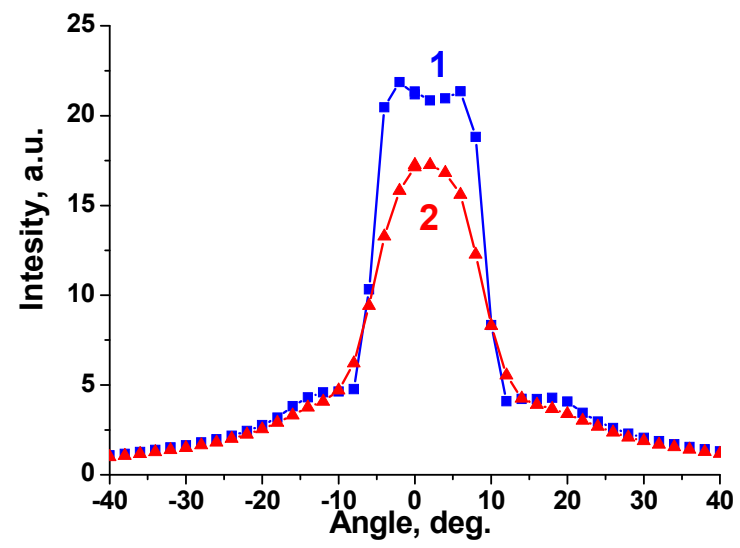

Figure 7 - Angular distribution of intensity of the reference radiation source UVB at a injection current of $100 \mathrm{~mA}: 1$ - without and 2 - with a holographic filter

As can be seen from the figure 4, the use of UV holographic filter as a diffuser allows to improve the angular distribution of the radiation intensity of the reference LED sources. In this case, the loss of radiation power does not exceed $20 \%$.

\section{Conclusion}

The UV-LED sources with conical type of reflectors for UVA, UVB and UVC ranges, which may be suitable for UV precision metrology were created. It was shown that the use of a conical diffuser leads to a significant $(30 \%)$ increase in the radiation power density in comparison with cylindrical diffuser. The intensity of the reference LEDs is within $\pm 10^{\circ}$ from the optical axis for 265 and $300 \mathrm{~nm}$, and about $\pm 15^{\circ}$ for $365 \mathrm{~nm}$. The values of the optical radiation density power at wavelengths of $265 \mathrm{~nm}, 300 \mathrm{~nm}$ and $365 \mathrm{~nm}$ with FWHM $10.5 \mathrm{~nm}$, $16 \mathrm{~nm}$ and $9.5 \mathrm{~nm}$ were witch $1,17 \mathrm{~W} / \mathrm{m}^{2}, 2,86 \mathrm{~W} / \mathrm{m}^{2}$ and $229,03 \mathrm{~W} / \mathrm{m}^{2}$ respectively. It is shown that the overlap of the neighboring CIE UV spectral ranges of the radiation of UV-LED sources is a little. The use of a UV holographic filter made it possible to increase the uniformity in the far-field radiation, with small power losses. Good spatial characteristics of the radiation of compact reference UV LED sources, as well as their high short-term and longterm stability will improve the measurement accuracy in the UV range. The UV-LED sources will be suitable for UV precision metrology.

\section{References}

CIE 2015. CIE 216:2015. EPPELDAUER, G.P. et al. Calibration procedure for UV-365 integrated irradiance measurements. Proceedings of 28th CIE Session 2015, Vol.1 Part 2, 1351 - 1364.

NIKANENKA, S. et al. 2017. Reference UV LED Sources. Smart Lightning for Better Life: Proceedings of the Conf. at the CIE Midterm Meeting 2017, 984 - 989.

NICHIA CORPORATION. Specification for UV LED.: http://www.nichia.co.jp/specification/ products/led/NVSU333A-E.pdf.

RUS 2011. Nikanenka S.V., Lutsenko E.V., Danilchyk A.V. Etalonnyij monohromnyij svetodiod [Reference monochrome LED]. Patent RF, no. 115889, 2011.

RUS 2012. Nikanenka S.V., Lutsenko E.V., Danilchyk A.V. Etalonnyij istochnik na osnove belogo svetodioda [Reference radiation source based on white LED]. Patent RF, no. 115890, 2012.

NIKANENKA, S. et al. 2014. Setup for measurement of the optical characteristics of UV-NIR solid-state light sources emission. Proceedings of NEWRAD 2014, $350-351$. 